\title{
Endomyocardial Fibrosis and the Prothrombotic State: From Hypercoagualability to Protien C Deficiency
}

Prabha Nini Gupta*, Praveen Velappan, Abdul Mansoor and Siju B Pillai

Department of Cardiology, Medical College, Trivandrum, India

\begin{abstract}
Thrombosis and endomyocardial fibrosis have coexisted for a long time. Earlier authors like Shaper, De Arbela and Davies have commented on the prevalence of large intracardiac thrombi in endomyocardial fibrosis. In three different reports Gupta PN, has also commented on intracardiac thrombi and their sequelae as thromboembolism in the past. We review here the possibility that apart from the basic intracavitary stasis due to chamber dilatation there may be an additional haematological defect in endomyocardial fibrosis. We review our previous studies on Protein $\mathrm{C}$ in endomyocardial fibrosis and the reduced platelet aggregation with collagen (but normal aggregation with $A D P$ ) that we had seen in our endomyocardial fibrosis patients. We postulated that these defects would add to the intracardiac thrombosis seen in endomyocardial fibrosis.
\end{abstract}

Keywords: Thrombosis; Intra-cardiac thrombi; Endomyocardial fibrosis; Protein C deficiency; Platelet function

\section{Introduction}

Endomyocardial fibrosis is a disease of unknown aetiology that has been found to be related to eating food grown on laterite soil [1]. This soil is supposed to be deficient in Magnesium. It has been observed that in this scenario, more heavy metals like Cerium and thorium enter the body of patients and experimental animals and even plant tissue cultures [2-6].

These heavy metals may deposit themselves in the bone marrow of the patient and cause pancytopenia and anaemia. We have earlier performed a multivariate analysis of factors leading to early death in endomyocardial fibrosis [7]. Strangely the presence of anaemia was one univariate predictor of poor prognosis. Patients with haemoglobin of below $10 \mathrm{~g} / \mathrm{dl}$ had a poor survival.

We have time and again found EMF patients with severe unexplainable anaemia, such that we have been forced to give repeated packed cell transfusions. No source of bleeding except mild gastric erosions has been seen by us. And, these patients often had a total count of just $4000-4500 \mathrm{cell} / \mathrm{cc}$. So, it is possible that the bone marrow of these patients has been supressed by the heavy metals deposited there.

The studies of Valiathan and Kartha, were performed with emf heart tissue [2,3]. Apart from this severe anaemia, another haematological abnormality has been found in EMF (endomyocardial fibrosis) [6-8].

This is large intra-cavitarythrombi. Of course, thrombi can occur even in any large chamber with stasis and slow flow [9]. But, if a historical review is made, the thrombosis in EMF appears to be extensive, and may be a little out of proportion to the degree of chamber enlargement and stasis.

So, we will briefly review some of the older studies of thrombosis in EMF and discuss two abnormalities we have previously studied.

\section{Does significant thrombosis occur in endomyocardial fibrosis?}

Davies and Ball were the first to describe the autopsy findings in endomyocardial fibrosis and its accompanying intra-cavitary thrombosis [10].

This was first commented on by Shaper and Wright [11]. They studied the autopsies of patients who had died from endomyocardial fibrosis and tried to study the relationship between the cardiomyopathy, intra-cardiac thrombosis and embolism. They found intra-cardiac thrombi in $47 \%$ of the 123 hearts examined. The maximum number of thrombi was in the left ventricle (22/57), next the right atrium had 17/57. The right ventricle had only 4 thrombi and the left atrium had only 1 . They were not really sure whether embolism does occur in endomyocardial fibrosis. But, they commented that embolism without infective endocarditis occurred in their series in 18 patients (15\%). The common sites of embolism were peripheral vessels, the spleen, with splenic infarcts and renal and cerebral infarctions did occur. Pulmonary embolism occurred with DVT in one case.

They believed that thrombosis was a part of the pathogenesis of the disease. Case number two in the series of Black and Fowler also died of pulmonary embolism [12]. She had a large thrombus in her right atrium on post-mortem. Her lungs showed both old and new pulmonary infarcts, showing that possibly anticoagulation would have prevented death in her. Their case 4 also had a large friable thrombus in the left ventricle. This patient was a middle aged man who had numerous infarcts in his kidneys probably due to embolism [13].

Again, Shaper and Hutt have not only graded endomyocardial fibrosis in their necropsy study but again commented on the incidence of intra-cardiac thrombi. Here 74 cases $(43 \%)$ had intra-cardiac thrombi. They also commented on concomitant rheumatic heart disease in 7 cases. Of these cases 36 patients had embolic phenomenon in the absence of bacterial endocarditis $16 \%$ had embolism due to pure endomyocardial fibrosis [14].

We would specially like to describe the endomyocardial fibrosis

*Corresponding author: Prabha Nini Gupta, Department of Cardiology, Medical College, T/C 5/2091, Near Sri Krishna Temple, Cheruvekkal, Srikaryam Trivandrum-695011, India, Tel:917736828055, 919847272168; E-mail: ninigupta@gmail.com

Received November 14, 2013; Accepted December 24, 2013; Published December 29, 2013

Citation: Gupta PN, Velappan P, Mansoor A, Pillai SB (2013) Endomyocardial Fibrosis and the Prothrombotic State: From Hypercoagualability to Protien $C$ Deficiency. J Blood Disorders Transf 5: 187. doi: 10.4172/2155-9864.1000187

Copyright: @ 2013 Gupta PN, et al. This is an open-access article distributed under the terms of the Creative Commons Attribution License, which permits unrestricted use, distribution, and reproduction in any medium, provided the original author and source are credited. 
described from Bahia Brazil, Andrade and Guimaraes [14]. Here they describe 4 cases of endomyocardial fibrosis and please note that in their Table 2 they have put the TC and DC of their patients. All four patients have a total count of 5800, 4000, 2800, or 6000 each. Again, they described organized thrombi in 3 of their 4 cases, 3 of these were in the right atrium and one was a ball valve thrombus of the size $5.5 \mathrm{~cm}$.

\section{Is there a hypercoagulable state in Endomyocardial fibrosis?}

Protein C has been called the "Nature's Silver bullet" for anticoagulation meaning the Zymogen Protein $\mathrm{C}$ getting activated to activate Protein C by Bruley and Strieff [15]. This natural anticoagulant anticoagulates when and where it is necessary without increased bleeding. The prevention of clots allows for normal blood blow. So it is obvious that deficiency of protein $\mathrm{C}$ would allow excess coagulation to occur. The normal levels of Protein $\mathrm{C}$ activity have been described as $125 \%, 150 \%$ and $200 \%$ and this prevents clotting without allowing any bleeding. So obviously if there is a Protein $\mathrm{C}$ deficiency excess clotting should follow.

So from our brief illustration it is true that a large proportion of endomyocardial fibrosis patients have intra-cardiac thrombi. What could be the cause of these thrombi? Could it be a deficiency of natural anticoagulants like ProtienC, Protien S or antithrombin III? Or could it be due to some inherent platelet abnormality or is it just due to statis in large dilated cavities?

Echocardiographic evidence of thrombi in five patients with embolism has also been previously described (Heart) Heart Asia and Heart Asia by us [7-9].

Now the question is, is it because of the large atrial cavities? Or is it because of an associated underlying hyper-coagulable state.

\section{The coagulation cascade: Normal or abnormalin EMF?}

We studied protein $\mathrm{C}$ in patients with EMF and found that they have type 1 and Type 2 deficiency of protein C. We also found that they have reduced collagen induced platelet aggregation. We discuss this in the following paragraphs [16].

The study of Sapru et al. could not find any significant abnormality in the superficial clotting parameters [17]. So Gupta, et al. (Accepted for publication in J of Blood Disorders and Transfusion [16] found that both Protein $\mathrm{C}$ in endomyocardial fibrosis and platelet aggregation are deranged in endomyocardial fibrosis [18].

Classically Protein C deficiency due to congenital reasons has been associated with deep venous thrombosis [19]. But newer reports link Protein $\mathrm{C}$ deficiency to intra-arterial thrombosis, blindness, stroke or even purpurafulminans [20-23]. However, an interesting recent report has reported gross intra-cavitary thrombosis with protein $\mathrm{C}$ deficiency. In a report by Ercan et al. cardiac thrombi have been observed in a patient with both Protein C and Protein S deficiency [23]. Here transthoracic echocardiography showed large multiple floating thrombi in the right ventricle and right atrium. The patient had recurrent pulmonary embolism. The pictures shown in the article are very similar to those seen in endomyocardial fibrosis. He was treated with Daltaparin sodium injections, aspirin and clopidogrel. He improved within 96 hours.

\section{Protein $\mathrm{C}$ deficiency and EMF}

We report here the results of our protein C estimation in endomyocardial fibrosis patients. It was low. Some patients had type 1 deficiency and some had type 2 deficiencies. We believe this is the first report of protein $\mathrm{C}$ deficiency in endomyocardial fibrosis.
As seen from the data, EMF patients have protein C deficiency, either type 1 or type 2 [16]. Whether this deficiency leads to increased intravascular coagulation may have to be validated by larger studies. At the time we performed this we were limited by the number of tests available in 1 kit. We utilized the entire kit (Table 3) [16].

Brulley has called Protein $C$ the natural anticoagulant. He postulates that in nature the Protien C levels range around $125 \%$ to $200 \%$ and prevent both clotting and thrombosis without causing bleeding [16]. As can be seen in our patients the values averaged around $60-70 \%$ Protien C functional activity. Hence obviously these levels were consistant with increased thrombosis. Currently all patients followed up by us are on warfarin so they may not develop thrombi. The figures shown below illustrate this point. The patient shown used to have large intra atrial thrombi in her right atrium. But now because of continuous anticoagulation she does not have any thrombi (Figures 1-3).

\section{Platelet abnormalities in endomyocardial fibrosis}

Crawford et al. studied 5 HT in platelets in EMF patients. They found that the platelet abnormalities that occur in carcinoid syndrome do not occur in endomyocardial fibrosis [24].

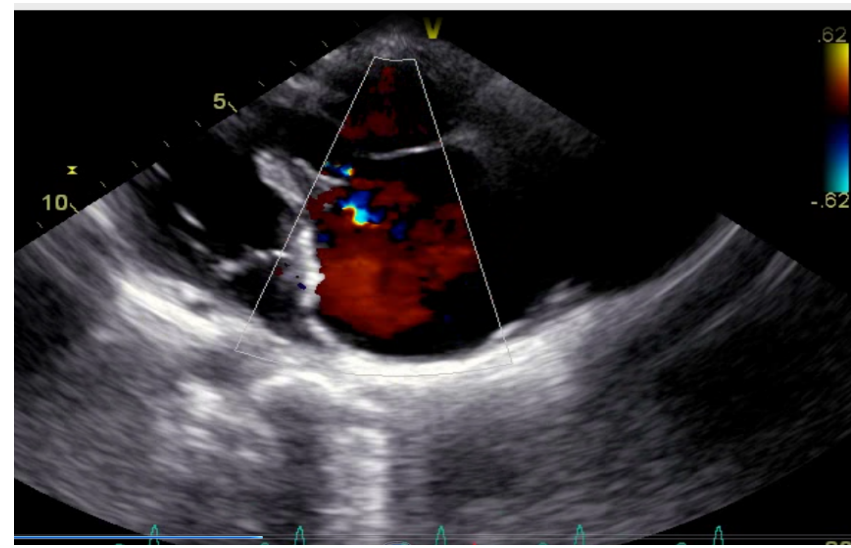

Figure 1: Showing the echocardiogram of a patient with endomyocardia fibrosis. She had been on Warfarin for a long time; hence no intracardiac thrombus is seen now. At present she stopped warfarin due to financial reasons. $680 \mathrm{~K}$.

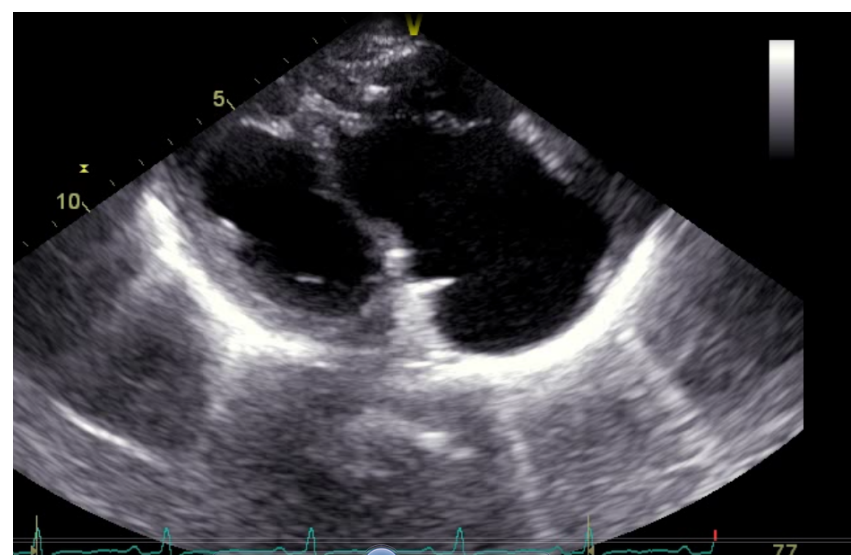

Figure 2: Note the typical calcified totally obliterated right ventricle and the massively dilated right ventricle. A patient with endomyocardial fibrosis. The same patient as above. The Doppler shows mild tricuspid regurgitation. $751 \mathrm{~K}$. 


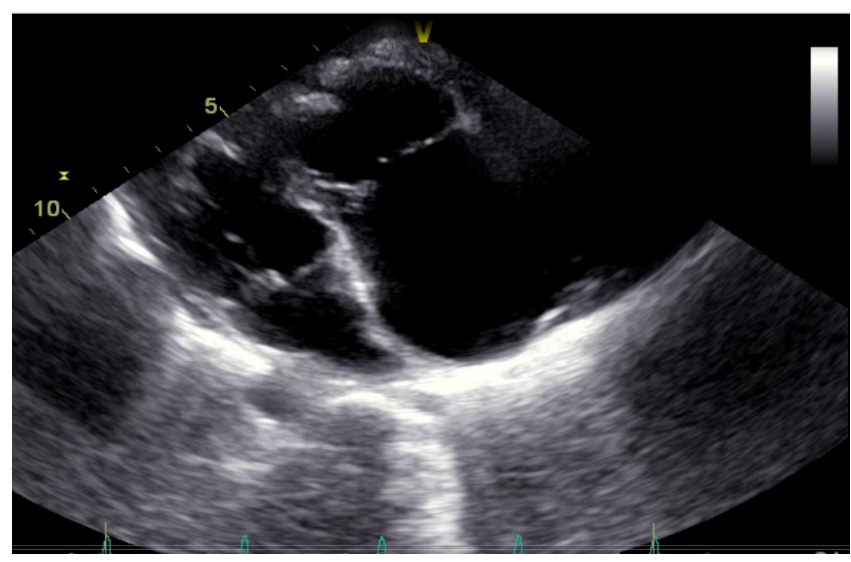

Figure 3: Another echocardiogram of the same patient with endomyocardial fibrosis. The right ventricle shows obliteration and calcification.

\begin{tabular}{|c|c|c|c|l|l|}
\hline Agonist & \multicolumn{4}{|c|}{ Aggregation rate (Mean \pm SE ) } & \multicolumn{1}{c|}{ t test } \\
\hline & Normal controls & $\mathbf{n}$ & EMF patients & $\mathbf{n}$ & \\
\hline Adrenaline (12 mM) & $0.1335 \pm .0379$ & 3 & $0.0618 \pm .016$ & 5 & NS \\
\hline Collagen (40 microg) & $0.1424 \pm .0284$ & 7 & $0.0511 \pm .007$ & 8 & $\mathrm{p}<0.005$ \\
\hline ADP (4.3 microM) & $0.74904 \pm .0204$ & 7 & $0.0615 \pm .008$ & 10 & NS \\
\hline
\end{tabular}

NS: Non-significant

Table 1: Aggregation rates of platelet-rich plasma prepared from normal subjects and EMF patients in response to various agonists [25]

\begin{tabular}{|l|l|}
\hline $\begin{array}{l}\text { Storage pool } \\
\text { disease }\end{array}$ & $\begin{array}{l}\text { Other manifestations- epistaxis , menorrhagia, easy bruising, } \\
\text { autosomal recessive. }\end{array}$ \\
\hline $\begin{array}{l}\text { Hermansky- } \\
\text { Pudlak Syn- } \\
\text { drome }\end{array}$ & $\begin{array}{l}\text { occlulocutaneous albinism, platelet function abnormality, } \\
\text { congenital neutropenia, pulmonary fibrosis and granulomatous } \\
\text { colitis }\end{array}$ \\
\hline $\begin{array}{l}\text { Quebec platelet } \\
\text { disorder }\end{array}$ & bleeding, autosomal dominant (unlikely) \\
\hline $\begin{array}{l}\text { Glanzmann's } \\
\text { thrombasthenia }\end{array}$ & $\begin{array}{l}\text { Was described in 1918-has impaired aggregation of platelets to } \\
\text { collagen, ADP or epinephrine-causes menorrhagia, petechial } \\
\text { and purpura. It is autosomal dominant. }\end{array}$ \\
\hline
\end{tabular}

Table 2: Could our patients with endomyocardial fibrosis have any of these ?

\begin{tabular}{|c|c|c|c|c|c|}
\hline \multicolumn{6}{|c|}{$\begin{array}{c}\begin{array}{c}\text { Protein } \mathrm{C} \text { levels in patient and controls (Patients with Endomyocardial } \\
\text { fibrosis) }\end{array}\end{array}$} \\
\hline & & & Patients (18) & Controls (18) & t test \\
\hline \multirow{2}{*}{\multicolumn{3}{|c|}{ Functional Assay }} & $(4 \%-130 \%)$ & $(28.87 \%-210 \%)$ & \\
\hline & & & $60.52-28.06 \%$ & $103+44.58$ & $p<0.01$ \\
\hline By $\mathrm{Im}$ & nunoelectroph & eresis & $79.73+26.88 \%$ & $85.23+30.02 \%$ & NS \\
\hline \multicolumn{6}{|c|}{ Types of Deficiency of Protein C seen among patients and controls } \\
\hline \multirow{2}{*}{ Patients } & Sample size & Normal & Type 1 & Type 2 & Atypical \\
\hline & 8 & 1 & 8 & 8 & 1 \\
\hline Control & 18 & 12 & 3 & 1 & 2 \\
\hline
\end{tabular}

Jamaludeen found a diminished collagen-induced platelet aggregation rate in endomyocardial fibrosis. (Presented in the International Symposium on Heart Disease and Annual meeting of the International Society for Heart Research) (Indian Section). The abstract came in the Indian Journal of Heart Research, Abstract issue, Feb 1988 [25].

In this study possible alterations of platelet behaviour were investigated by studying platelet aggregation in Platelet Rich Plasma
(PRP). The novel spectrophotometric method of Jamaludeen and Krishnan which measures single platelet recruitment into aggregates was employed for this study [26]. The patients were off drugs known to effect platelet function for 1 week before the tests and age and sex matched controls were chosen. Fasting blood was drawn at the same time ( $8 \mathrm{am})$ every morning without a tourniquet into siliconized glass syringes and transferred immediately to acid-citrate-dextrose solution in the proportion 9:1. The anticoagulated blood was centrifuged at 40x for 20 minutes to obtain PRP (PRP, Platelet Rich Plasma). This was diluted with autologous platelet poor plasma to make the absorbance value at $540 \mathrm{~nm}=1$. Aggregation in duplicate was carried out within one hour of blood collection. The results are shown in Table 1.

The platelets of EMF patients seemed to have less platelet aggregation with collagen. This may have been because the platelets had already been activated by intravascular clotting or that the platelets themselves had an inherent defect so that they showed reduced aggregation with collagen and marginally less aggregation with adrenaline when compared to controls [27].

It was believed that this is due to derangements in the arachidonate pathway, the ADP pathway appeared normal.

Diminished platelet aggregation with collagen has been described in 3 different situations. One is storage pool disease [28]. Here the platelets have diminished stores of ADP so their response to aggregation with collagen is diminished. But, they also have diminished response to aggregation with ADP. Our EMF patients had normal aggregation responses to ADP. The second condition where diminished collagen induced platelet aggregation is seen, is seen in patients on aspirin. We were very careful not to include any patient on either aspirin or ticlopidine. So this may not also be the reason for the abnormal response to collagen. We believe the third reason may be the reason for diminished collagen induced platelet aggregation, iron deficiency anaemia has been shown to cause reduced collagen induced platelet aggregation. Correction of anaemia has been shown to correct is abnormality [29].

It is possible our patients had this third problem because we have one or two patients in whom the anaemia is so severe as to require frequent blood transfusion. These patients are on warfarin as this has been shown to improve survival in EMF patients [8]. But the INR of these patients is kept at 1 to 1.3 by us. As we have found, these patients tend to have bleedingper vaginum at menstrual periods more than usual, with higher doses of warfarin, in spite of normal INRs. So it may be a platelet abnormality caused by the severe iron deficiency anaemia. Our patient illustrated in the report with a very large RA thrombus actually usually has a haemoglobin of 6 gms till we give her multiple transfusions and her TC is around 4000 with normal platelet counts [9].

The following are congenital deficiencies of platelets. Any of these could be a cause of the diminished platelet aggregation with collagen seen in our report. Andrea GA describes the common inherited platelet abnormalities [27]. Of these Bernard-Soulier syndrome does not have to be looked into as it is a bleeding disorder. Inherited thrombocytopathies have been classified according to the mode of platelet abnormality. Bernard-Soulier syndrome is a disease of platelet adhesion. Disorders of platelet activation are autosomal recessive and have no name. These are due to defective activation with ADP. Disorders of platelet aggregation are Glansmann's thrombasthenia. This is autosomal recessive disorder. Endomyocardial fibrosis has been associated with this disease.

Storage pool disease $[30,31]$. These are otherwise called storage pool disorders and are platelet secretion disorders. Impaired platelet aggregation has been found in this group of disorders. It is possible our 
Citation: Gupta PN, Velappan P, Mansoor A, Pillai SB (2013) Endomyocardial Fibrosis and the Prothrombotic State: From Hypercoagualability to Protien C Deficiency. J Blood Disorders Transf 5: 187. doi: 10.4172/2155-9864.1000187

Page 4 of 5

patient had this disorder. This is an autosomal recessive disorder. These patients often manifest as epistaxis and menorrhagia and easy risibility. We have observed this before.

In patients with Grey platelet syndrome severe deficiency of collagen induced platelet aggregation has been noted [31].

Quebec platelet disorder and Heramansky-Pudlak syndrome should also be considered as both have diminished aggregation to collagen. But the QPD is considered a bleeding disorder so this is unlikely in endomyocardial fibrosis. We point out Hermansky-Pudlak syndrome because of the association of diminished platelet aggregation with collagen and congenital neutropenia. We have observed neutropenia in some patients with EMF and note the report from Brazil quoted above [15]. They also have gross neutropenia.

We have had EMF patients with severe menorrhagia, hence we also consider grey platelet syndrome (Table 2). Further types of Inherited Giant platelet Disorders have been reviewed in by Mhawech and Saleem [30].

Glanzmann's thrombasthenia was first described in 1918 as a bleeding disorder. But, one case of EMF by independent workers has been described to have Glanzmann's thrombasthenia. In this disorder, there is impaired platelet aggregation to collagen [32]. It typically manifests as purpura, epistaxis, petechial, gingival haemorrhages and menorrhagia and subcutaneous haematomas.

It is of interest that a case of endomyocardial fibrosis has been described with Glanzmann's thrombasthenia. Tullu et al. report a case of left ventricular endomyocardial fibrosis in a 6 year old male with a left ventricular thrombus and endomyocardial fibrosis. This boy also had Glanzmann's thrombasthenia [31].

More studies are required to understand the relationship of various platelet disorders and coagulation studies with endomyocardial fibrosis, such as did the coagulation disorder occur first or the structural disease?

Newer studies of intracardiac thrombosis in endomyocardial fibrosis include Aggarwal et al. [32-36].

Anyway endomyocardial fibrosis still remains an enigma and it definitely affects the heamopoetic system with many patients having low TC (total count) and DC (differential count).So anaemia and platelet function abnormalities co-existing is not a surprize.

\section{References}

1. Sivasankaran S (2009) Restrictive cardiomyopathy in India: the story of a vanishing mystery. Heart 95: 9-14.

2. Valiathan MS, Kartha CC, Panday VK, Dang HS, Sunta CM (1986) A geochemical basis for endomyocardial fibrosis. Cardiovasc Res 20: 679-682.

3. Valiathan MS, Kartha CC, Eapen JT, Dang HS, Sunta CM (1989) A geochemical basis for endomyocardial fibrosis. Cardiovasc Res 23: 647-648.

4. Valiathan SM, Kartha CC (1990) Endomyocardial fibrosis--the possible connexion with myocardial levels of magnesium and cerium. Int $\mathrm{J}$ Cardiol 28: 1-5.

5. Kartha CC, Valiathan MS, Eapen JT, Rathinam K, Kumary TV, Kutty VR. (1993) Enhancement of cerium levels and associated myocardial lesions in hypomaneseamic rates fed on cerium-adulterated diet. In: Somers K, Kartha CC, Valiathan (Eds.), in Endomyocardial fibrosis, Oxford University Press, New Delhi, pp: 243-253

6. Nair RR, Gupta PN, Valiathan MS, Kartha CC, Eapen JT, et al. (1989) Enhanced Cerium concentration in magnesium deficient plants. Current Science 58: 696-697.

7. Gupta PN, Valiathan MS, Balakrishnan KG, Kartha CC, Ghosh MK (1989) Clinical course of endomyocardial fibrosis. Br Heart J 62: 450-454
8. Subair M Gupta PN (2011) The Medical treatment of Endomyocardial Fibrosis Heart Asia 3: 120-123.

9. Gupta PN, Subair MK, Vishwanathan S, Thomas JM, Kumar BR (2013) A uncommon picture of endomyocardial fibrosis:no embolism yet. Heart Asia 5 171-73.

10. Davies JN, Ball JD (1955) The pathology of endomyocardial fibrosis in Uganda Br Heart J 17: 337-359.

11. Shaper AG, Wright DH (1963) Intracardiac Thrombosis And Embolism In Endomyocardial Fibrosis In Uganda. Br Heart J 25: 502-508.

12. Black M, Fowler JM (1965) Endomyocardial Fibrosis in Britain. Br Med J 1: 682-686.

13. Shaper AG, Hutt MS, Coles RM (1968) Necropsy study of endomyocardial fibrosis and rheumatic heart disease in Uganda 1950-1965. Br Heart J 30: 391-401.

14. Andrade ZA, Guimaraes AC (1964) Endomyocardial Fibrosis In Bahia, Brazil. $\mathrm{Br}$ Heart J 26: 813-820.

15. Bruley DF, Streiff MB (2013) Nature's "silver bullet" for anticoagulation: mechanism of Zymogen Protein $C$ to Activated Protein C. Adv Exp Med Biol 765: 15-21.

16. Gupta PN, Balakrishnan KG, Kartha CC (2013) Diminished Protein C in Endomyocardialfibrosis:The possible significance." J of Blood Disorders and Transfusion 4: 170

17. Sapru R P, Balakrishnan KG, Subramoniumlyer S, Shanmugan J (1983 Haematological, Biochemical, Immunological and Electrophysiological Studies in Endomyocardial Fibrosis. In: Sapru RP (Eds.), Endomyocardial Fibrosis in India, Indian Council of Med Research press, New Delhi, pp: 175-183.

18. Bovill EG, Bauer KA, Dickerman JD, Callas P, West B (1989) The clinical spectrum of heterozygous protein $C$ deficiency in a large New England kindred. Blood 73: 712-717.

19. Kottke-Marchant K Comp P (2002) Laboratory issues in diagnosing abnormalities of protein $\mathrm{C}$, thrombomodulin, and endothelial cell protein $\mathrm{C}$ receptor. Arch Pathol Lab Med 126: 1337-1348.

20. Cho YP, Lee DH, Jang HJ, Kim JS, Han MS, et al. (2002) Peripheral arteria insufficiency associated with protein $\mathrm{C}$ deficiency. $\mathrm{Br} \mathrm{J}$ Radiol 75: 843-846.

21. Knoebl PN (2008) Severe congenital protein C deficiency: the use of protein C concentrates (human) as replacement therapy for life-threatening bloodclotting complications. Biologics 2: 285-296.

22. Patel ML, Sachan R, Gupta KK, Seth G (2013) Ischemic Stroke in Young due to combined Protein $\mathrm{C}$ and $\mathrm{S}$ deficiency. Journal of Case reports 3:19-23.

23. Ercan E, Tengiz I, Sekuri C, Sahin F, Aliyev E, et al. (2004) Cardiac thrombi in a patient with protein-C and $S$ deficiencies: a case report. Thromb J 2: 2.

24. Crawford MA, Hansen IL, Somers K (1970) Studies on platele 5-hydroxytryptamine in East Africans. Br J Nutr 24: 385-392.

25. Jamaludeen G (1988) Unpublished observations. Annual meeting of the International Society for Heart Research.

26. Jamaluddin MP, Krishnan LK (1987) A spectrophotometric method for following initial rate kinetics of blood platelet aggregation. J Biochem Biophys Methods 14: 191-200

27. Andrea DG, Chetta M, Margaglione M (2009) Inherited platelet disorders: thrombocytopenias and thrombocytopathies. Blood Transfus 7: 278-292.

28. Calişkan U, Oner AF, Kabakuş N, Koç H (1999) Diminished platelet aggregation in patients with iron deficiency anemia. Clin Appl Thromb Hemost 5: 161-163.

29. Nurden P, Jandrot-Perrus M, Combrié R, Winckler J, Arocas V, et al. (2004) Severe deficiency of glycoprotein $\mathrm{VI}$ in a patient with gray platelet syndrome. Blood 104: 107-114.

30. Mhawech P, Saleem A (2000) Inherited giant platelet disorders. Classification and literature review. Am J Clin Pathol 113: 176-190.

31. Tullu MS, Vaideeswar P, Pandit SP, Lahiri KR (2007) Glanzmann thrombasthenia with endomyocardial fibrosis: a thrombotic paradox. Int J Cardiol 114: 401-402.

32. Aggarval AA, Sinha B, Rajpal S, Dwivedi S, Sharma V (2009) Right Ventricular Endomyocardial Fibrosis Presenting with Ventricular tachycardia and Apical Thrombus-An Interesting Presentation. Indian Pacing and Electrophysiology Journal 9: 360-363. 
Citation: Gupta PN, Velappan P, Mansoor A, Pillai SB (2013) Endomyocardial Fibrosis and the Prothrombotic State: From Hypercoagualability to Protien C Deficiency. J Blood Disorders Transf 5: 187. doi: 10.4172/2155-9864.1000187

Page 5 of 5

33. Gonçalves LF, Souto FM, Faro FN, Oliveira JL, Barreto-Filho JA, et al. (2012) Biventricular thrombus and endomyocardial fibrosis in antiphospholipid syndrome. Arq Bras Cardiol 99: e162-165.

34. Salanitri GC (2005) Endomyocardial fibrosis and intracardiac thrombus occurring in idiopathic hypereosinophilic syndrome. AJR Am J Roentgenol 184: 1432-1433.
35. Fernández Vázquez E, Lacárcel Bautista C, Alcázar Navarrete B, Casado Moreno I, Espejo Guerrero A, et al. (2003) [Chronic thromboembolic pulmonary hypertension associated with endomyocardial fibrosis of the right ventricle] Arch Bronconeumol 39: 370-372.

36. Mocumbi AO, Ferreira MB, Sidi D, Yacoub MH (2008) A population study of endomyocardial fibrosis in a rural area of Mozambique. N Engl J Med 359: 43-49. 